\title{
Erratum to: Probabilistic seismic hazard analysis of interconnected infrastructure: a case of Iranian high-pressure gas supply system
}

\section{A. Golara}

Published online: 20 March 2014

(C) Springer Science+Business Media Dordrecht 2014

\section{Erratum to: Nat Hazards \\ DOI 10.1007/s11069-014-1087-6}

In publication process, Fig. 4 is omitted and it has been mistakenly replaced with Fig. 1.

The online version of the original article can be found under doi:10.1007/s11069-014-1087-6.

A. Golara $(\bowtie)$

National Iranian Gas Company (NIGC), Tehran, Iran

e-mail: a.golara@gmail.com 


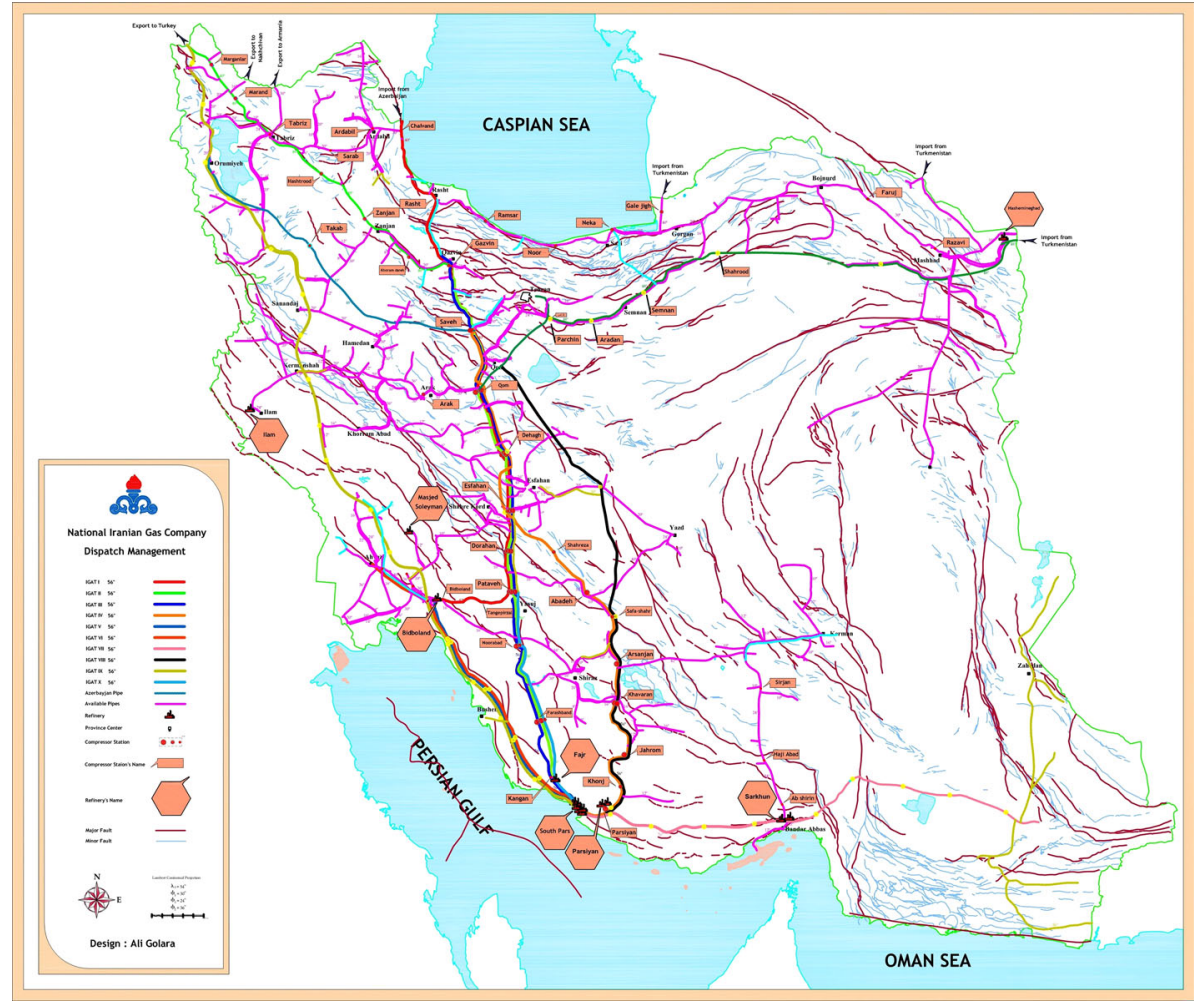

Fig. 4 The location of recent active major and minor faults on Iranian gas supply system 